\title{
Oxygen availability in model solutions and purées during heat treatment and the impact on vitamin $\mathrm{C}$ degradation
}

\author{
Anna-Lena Herbig, Jean-François Maingonnat, Catherine M.G.C. Renard* \\ INRA, Université d'Avignon et des Pays du Vaucluse, UMR408 SQPOV (Sécurité et Qualité des Produits d'Origine Végétale), F-84000 Avignon, France
}

\begin{abstract}
A B S T R A C T
Oxygen availability in different media during heat treatment $\left(8 \mathrm{~h}\right.$ at $\left.80^{\circ} \mathrm{C}\right)$ and the related vitamin $\mathrm{C}$ loss was assessed. Dissolved oxygen in water containing $3 \mathrm{mmol} \mathrm{kg}^{-1}$ of ascorbic acid decreased initially and seemed to be replaced by oxygen from the headspace in the course of time, as oxygen values increased again. In apple purée and carrot purée in contrast, oxygen was depleted within $60 \mathrm{~min}$. Vitamin $\mathrm{C}$ in ultrapure water was stable even in the presence of oxygen. A trigger seemed to be crucial to launch vitamin $\mathrm{C}$ degradation. $\mathrm{Fe}^{3+}$ ions added to water, but also the media Mc Ilvaine citrate-phosphate buffer ( $\mathrm{pH}$ 3.5) or apple purée, initiated degradation. Adding $\mathrm{Fe}^{3+}$ ions to apple purée did not accelerate vitamin

$C$ degradation but shifted the equilibrium between ascorbic acid and dehydroascorbic acid to the latter. Oxygen deprivation stabilized completely vitamin C, independently of the medium tested. A temperature decrease to 70 or $60{ }^{\circ} \mathrm{C}$, in contrast, had no effect on the degradation extent of vitamin $\mathrm{C}$ in water containing $20 \mu \mathrm{mol} \mathrm{kg} \mathrm{kg}^{-1} \mathrm{Fe}^{3+}$ ions but led to complete stability in apple purée.
\end{abstract}

Keywords:

Dissolved oxygen

Anaerobic condition

Ascorbic acid

Dehydroascorbic acid

Reheating

\section{Introduction}

Vitamin C is well known for exhibiting beneficial health properties (Block, 1991; Gale, Martyn, Winter, \& Cooper, 1995; Zandi et al., 2004). It is however susceptible to deterioration. In raw products, enzymes as for example polyphenol oxidase accelerate this reaction. Polyphenol oxidase catalyzes the oxidation of polyphenols which leads to consumption of ascorbic acid since it acts as reducer of generated quinones (Aka, Courtois, Louarme, Nicolas, \& Billaud, 2013). At elevated temperatures, where enzymes are inactive, degradation still proceeds in significant amounts. The aerobic degradation pathway of ascorbic acid proceeds faster than the anaerobic one, which only occurs to significant amounts over $120{ }^{\circ} \mathrm{C}$ (Dhuique-Mayer et al., 2007; Oey, Verlinde, Hendrickx, \& Van Loey, 2006; Verbeyst, Bogaerts, Van der Plancken, Hendrickx, \& Van Loey, 2013). The availability of oxygen is thus crucial for the fate of vitamin $C$ at an intermediate temperature range.

Oxygen is soluble in water up to $100{ }^{\circ} \mathrm{C}$ (Penicaud, Peyron, Gontard, \& Guillard, 2012) Its saturation is temperature and matrix dependent. An increase of temperature, salinity or ${ }^{\circ}$ Brix leads

\footnotetext{
* Corresponding author. INRA, UMR 408 SQPOV, Domaine St Paul, Site Agroparc, F-84914 Avignon Cedex 09, France.

E-mail addresses: Jean-Francois.Maingonnat@avignon.inra.fr (J.-F. Maingonnat), catherine.renard@avignon.inra.fr (C.M.G.C. Renard).
}

to a decrease of dissolved oxygen. Verbeyst et al. (2013) supposed that dissolved oxygen in strawberry and raspberry pastes in the range $80-120^{\circ} \mathrm{C}$ was quickly consumed and led to the plateau they observed in terms of vitamin $C$ degradation, even though heat treatment continued. Oxygen concentrations were however not measured simultaneously to degradation. In agar gel, a gradient of oxygen and vitamin C concentration occurs at $20^{\circ} \mathrm{C}$ in the course of time with higher degradation near the surface (Penicaud, Broyart, Peyron, Gontard, \& Guillard, 2011). The role of dissolved oxygen in citrus juice on vitamin $\mathrm{C}$ degradation at $90{ }^{\circ} \mathrm{C}$ was studied by nitrogen substitution of initial dissolved oxygen (Dhuique-Mayer et al., 2007). However, as gases' solubility is decreased by heat, it is very likely that in this study, the liberation counted also for nitrogen and thus the oxygen-to-nitrogen-ratio can be assumed to have changed in the headspace too. Hence, a lower vitamin C degradation rate which was associated to lower dissolved oxygen contents, was presumably rather a combination of headspace and dissolved oxygen depletion.

Up to now it is not known how fast oxygen is consumed at elevated temperatures and if it is replaced quickly from the headspace. In addition, other oxidizable components are present in real food products contributing to oxygen consumption. Dissolved oxygen measurements at higher temperatures were difficult to achieve in the past. Measurements at precise locations became possible due to development of oxygen sensors (Liebsch, Klimant, 
Frank, Holst, \& Wolfbeis, 2000) that can be installed on recipients' walls and are specially calibrated for elevated temperatures.

Besides oxygen, other food oxidants such as $\mathrm{Fe}^{3+}$ ions interfere in the degradation of ascorbic acid. $\mathrm{Fe}^{3+}$ ions accelerate the oxidation of ascorbic acid to dehydroascorbic acid and the hydrolysis of dehydroascorbic acid to 2,3-diketogulonic acid, by which the vitamin activity is lost (Serpen \& Gökmen, 2007). This seems to result from of a redox reaction with ascorbic acid being oxidized and $\mathrm{Fe}^{3+}$ ions being reduced to $\mathrm{Fe}^{2+}$ ions. $\mathrm{Fe}^{2+}$ ions, in turn, react in the Fenton reaction with hydrogen peroxide (Choe \& Min, 2005) which is formed during the oxidation of ascorbic acid (Boatright, 2016). However, it is not known if the concomitant presence of oxygen is necessary for the $\mathrm{Fe}^{3+}$ ion-caused oxidation. Under anaerobic conditions and in the presence of $\mathrm{Cu}^{2+}$ ions, the stability of ascorbic acid can almost completely be preserved in contrast to aerobic conditions where ascorbic acid degrades rapidly (Boatright, 2016).

The aim of the present study was to reveal oxygen availabilities in different media during heat treatment at $80{ }^{\circ} \mathrm{C}$ and to understand the influence of $\mathrm{Fe}^{3+}$ ions, ascorbic acid concentrations and temperature. Furthermore, the linked vitamin $\mathrm{C}$ degradation was investigated.

\section{Material and methods}

\subsection{Chemicals and food matrices}

2,2'-Bipyridyl, ascorbic acid, trichloroacetic acid, DLdithiothreitol, $\mathrm{Na}_{2} \mathrm{HPO}_{4}, \mathrm{NaH}_{2} \mathrm{PO}_{4} \mathrm{XH}_{2} \mathrm{O}, \mathrm{N}$-Ethylmaleimide and citric acid monohydrate were from Sigma-Aldrich (Deisenhofen, Germany). Ortho-phosphoric acid 85\%, Iron(III)chloride hexahydrate from VWR (Leuven, Belgium) and ethanol from by Fisher Scientific (Fair Lwan, NJ, USA).

Apple purée (brand: HIPP) and carrot purée (brand: POUCE) without added vitamin $C$ were purchased in a local supermarket in Avignon/France.

\subsection{Supplementation and heat treatment}

Ascorbic acid supplementation was carried out in corning tubes. After addition of ascorbic acid, samples were vortexed thoroughly, then transferred to a beaker and preheated to the respective temperature of interest while stirring. When temperature was achieved, the sample was immediately conveyed to a double walled system (Société Legallais, Montferrier-sur-Lez, France, Fig. 1) which was filled up to a height of $1 \mathrm{~cm}$. The inner diameter of the vessel was $4.5 \mathrm{~cm}$ and the depth of the inner volume $2.7 \mathrm{~cm}$. The double walled glass vessel was connected to a water bath (ED-19 Julabo, Seelbach, Germany) to maintain temperature of the medium. To avoid water evaporation, a plastic cap supported by silicon fat was put onto the top. As a consequence, the headspace became vapor saturated. Aliquots were withdrawn after the preheating step, corresponding to the initial value, and at the end of the heat treatment, and immediately deep-frozen $\left(\leq-18^{\circ} \mathrm{C}\right)$.

When the effect of oxygen deprivation was evaluated, nitrogen was bubbled into a stirred and heated solution. Subsequently, the solution was transferred to a $12.5 \mathrm{~cm}$ glass tube (diameter $1 \mathrm{~cm}$ ) which was filled up to $4.5 \mathrm{~cm}$ under nitrogen flow. The tube was closed with a cap including a septum and allowing thus to maintain anaerobic conditions. The heat treatment was carried out by putting the glass tubes in a block heater (Stuart; Roissy Charles de Gaulle, France).

\subsection{Oxygen measurement}

Planar oxygen sensors (Presens GmbH, Regensburg, Germany) with a diameter of $5 \mathrm{~mm}$ and calibrated up to a temperature of $80^{\circ} \mathrm{C}$ were stuck with silicon glue at the inner bottom, at a height of $1 \mathrm{~cm}$ and in the headspace region of the double walled glass vessel (Fig. 1). Oxygen was measured from the outside of the vessel via a polymer optical fiber connected to a Fibox 4 Transmitter (Presens $\mathrm{GmbH}$, Regensburg, Germany). Temperature in the vessel was measured by a sensor Pt100 (Presens GmbH, Regensburg, Germany) which was also linked to the Transmitter.

\subsection{Vitamin C analysis}

Vitamin C was quantified spectrophotometrically (Stevens, Buret, Garchery, Carretero, \& Causse, 2006). Approximately $500 \mathrm{mg}$ aliquots were taken and absorption was measured at $525 \mathrm{~nm}$ on a spectrophotometer (Safas Xenius, Monaco).

\section{Results}

\subsection{Treatment in water}

Ultrapure water served as reference medium. After transferring the preheated solution to the double walled system, oxygen contents reached equilibrium in approximately $15 \mathrm{~min}$ (Fig. 2A), and then remained stable at $0.07 \mathrm{mmol} \mathrm{L}^{-1}$ in all three locations until the end of the measurement time. The oxygen content is in the range reported by Penicaud et al. (2012) for ultrapure water at $80{ }^{\circ} \mathrm{C}$. Oxygen equilibrium in the headspace and the medium was attained at the same pace.

In water containing $3 \mathrm{mmol} \mathrm{kg}-1$ of ascorbic acid, oxygen contents dropped as in ultrapure water at the beginning of measurements (Fig. 2B). The decrease in the liquid was however higher than in the headspace, which can be ascribed to oxygen consumption by ascorbic acid. Oxygen was not entirely consumed even though ascorbic acid was in molar excess compared to oxygen (Fig. 2B). Since oxygen concentrations increased again, oxygen consumption and diffusion from the headspace into the medium seemed to compete and to lead to a dynamic equilibrium. In addition, as the oxygen consumption rate at the bottom and the surface of the medium was not significantly different, oxygen diffusion appeared to be a continuous and fast process at $80^{\circ} \mathrm{C}$. The headspace oxygen level was however not reached again in the medium within the $8 \mathrm{~h}$.

Furthermore, in spite of oxygen consumption and increase of dehydroascorbic acid, the overall vitamin $C$ content did not decrease (Fig. 2). Buettner (1988) observed also high stability of ascorbic acid when the medium was completely deprived of metals.

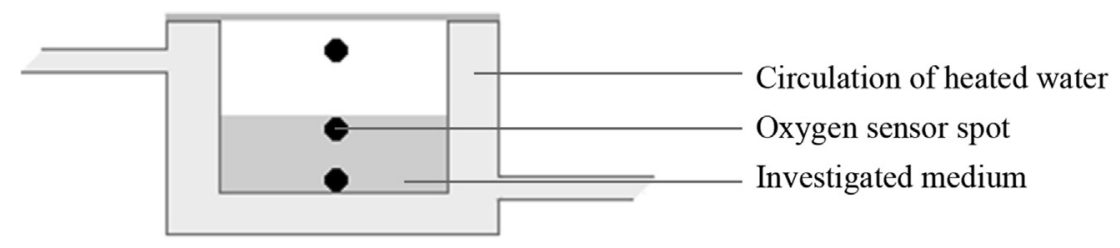

Fig. 1. Double-walled vessel containing medium and three oxygen sensor spots. 

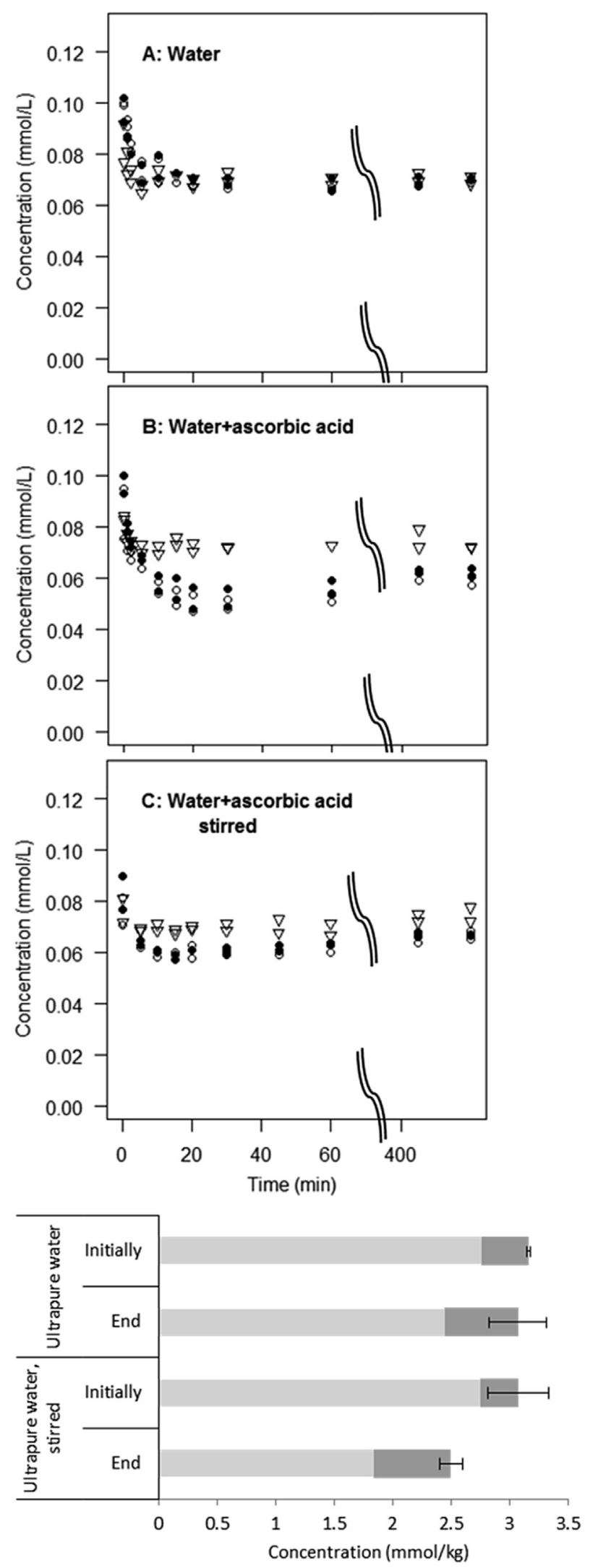

Fig. 2. Oxygen time course at $80^{\circ} \mathrm{C}$ in the $\nabla$ headspace, and in the $\bigcirc$ surface and the - bottom region of the medium. A: water, B: water containing ascorbic acid $\left(3 \mathrm{mmol} \mathrm{kg}{ }^{-1}\right)$, C: stirred water containing ascorbic acid $\left(3 \mathrm{mmol} \mathrm{kg}{ }^{-1}\right)$. And related vitamin $\mathrm{C}$ loss illustrated as bar plots, light grey: ascorbic acid, dark grey: dehydroascorbic acid.
Subsequently, the experiment was repeated while stirring of the solution. Oxygen values decreased less at the beginning but still to a lower level than in the headspace (Fig. 2C). Oxygen was replaced more easily when the contact to headspace was increased. A vitamin C loss of $20 \%$ was found.

\subsection{Buffer and food matrices}

Also in non-stirred Mc Ilvaine citrate-phosphate buffer ( $\mathrm{pH} 3.5$ ) that contained $3 \mathrm{mmol} \mathrm{kg}^{-1}$ of ascorbic acid, oxygen was more depleted in the medium compared to the headspace (Fig. 3A). A vitamin C loss of approximately $50 \%$ was observed (Fig. 3 ). The elevated variability of oxygen levels was also reflected by higher standard deviations of vitamin C contents. As reported by Buettner (1988), trace metals are detectable in many buffer solutions but not in double-distilled water, and might thus be responsible for vitamin C degradation in Mc Ilvaine citrate-phosphate buffer which was used in this study.

Oxygen decreased within 60 min down to anaerobic conditions in apple purée which was supplemented with $3 \mathrm{mmol} \mathrm{kg}^{-1}$ of ascorbic acid, and did not increase again until the end of experiment (Fig. 3B). Van Bree et al. (2012) reported that oxygen levels in the headspace decreased during vitamin $C$ degradation under their conditions, which was however not the case here indicating that oxygen could enter from the outside. The oxygen decrease in the medium was slightly slower near the surface compared to the bottom but still proceeded within $60 \mathrm{~min}$ and down to anaerobic values. The complete elimination of oxygen may be caused by additional oxidation reactions of other components in the apple purée such as polyphenols.

Furthermore, even if oxygen was consumed entirely, 30\% of vitamin $C$ was lost. This might be explained by oxidation due to a redox-reaction with polyphenols (Aka et al., 2013; Bradshaw, Barril, Clark, Prenzler, \& Scollary, 2011). In this reaction, ortho-quinones are reduced to the dihydroxyl corresponding molecule while ascorbic acid is oxidized to dehydroascorbic acid. This hypothesis was corroborated by the absence of a browning reaction at the very top surface when $3 \mathrm{mmol} \mathrm{\textrm {kg } ^ { - 1 }}$ of ascorbic acid was added (Supplementary data/Fig. 8).

In carrot purée, a decrease to anaerobic conditions, already within 20 min, was observed (Fig. 3C). As in apple purée, a slightly slower decrease was observed near the surface compared to the bottom. About $30 \%$ of vitamin C was lost (Fig. 3).

\subsection{Impact of $\mathrm{Fe}^{3+}$ ions}

Oxygen behavior was firstly studied in a blank consisting in water with $20 \mu \mathrm{mol} \mathrm{kg}{ }^{-1} \mathrm{Fe}^{3+}$ ions. As in ultrapure water, oxygen contents in all three oxygen sensor locations decreased in the first minutes down to one stable oxygen level which was of $0.08 \mathrm{mmol} \mathrm{L}^{-1}$ (Supplementary data/Fig. 9).

Subsequently, the concentration effect of $\mathrm{Fe}^{3+}$ ions on oxygen availability and vitamin $C$ stability was studied in water with $3 \mathrm{mmol} \mathrm{kg} \mathrm{kg}^{-1}$ of ascorbic acid in the presence of three different $\mathrm{Fe}^{3+}$ concentrations $\left(20,100,200 \mu \mathrm{mol} \mathrm{kg}{ }^{-1}\right)$. Oxygen decreased the fastest when the $\mathrm{Fe}^{3+}$ ion concentration was of $100 \mu \mathrm{mol} \mathrm{kg}{ }^{-1}$ and the slowest at a concentration of $200 \mu \mathrm{mol} \mathrm{kg}^{-1}$ (Fig. 4). The oxygen consumption time curve for water containing $20 \mu \mathrm{mol} \mathrm{kg} \mathrm{kg}^{-1} \mathrm{Fe}^{3+}$ ions was in between the two others. The difference of oxygen consumption rates was small but a similar trend was found for the corresponding vitamin $C$ degradation levels. In the presence of a $\mathrm{Fe}^{3+}$ ion concentration of 20 and $200 \mu \mathrm{mol} \mathrm{kg}{ }^{-1}$, degradation levels were lower than in the presence of $100 \mu \mathrm{mol} \mathrm{kg} \mathrm{kge}^{-1} \mathrm{Fe}^{3+}$ (Fig. 4). Higher oxygen concentrations and less degradation in the presence of $200 \mu \mathrm{mol} \mathrm{kg}-1$ compared to $100 \mu \mathrm{mol} \mathrm{kg}-1$ might be due to a 

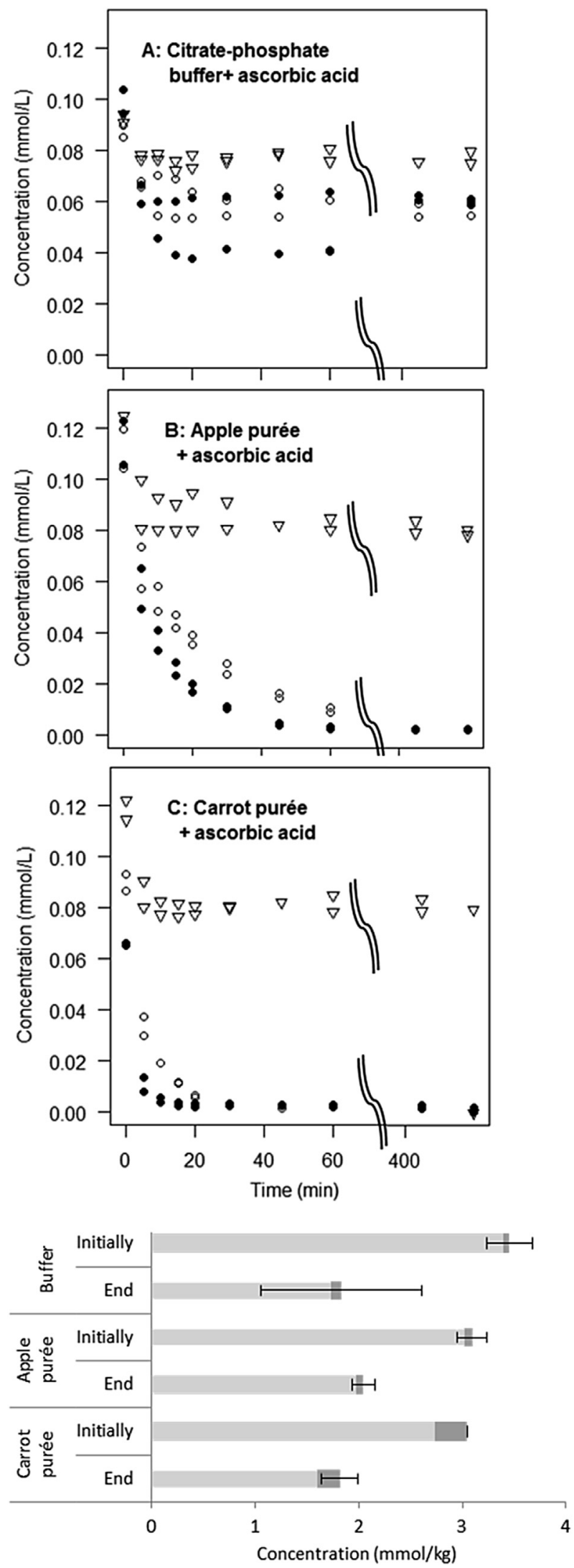

Fig. 3. Oxygen time course at $80{ }^{\circ} \mathrm{C}$ in the $\nabla$ headspace, and in the $\bigcirc$ surface and the - bottom region of the medium containing ascorbic acid $\left(3 \mathrm{mmol} \mathrm{kg}^{-1}\right)$. A: citratephosphate buffer, B: apple purée and C: carrot purée. And linked vitamin C loss depicted as bar plots, light grey: ascorbic acid, dark grey: dehydroascorbic acid.

changed equilibrium of Fenton reactions. On the one hand, $\mathrm{Fe}^{3+}$ ions accelerate ascorbic acid oxidation (Khan \& Martell, 1967), but on the other hand when superoxide anions encounter $\mathrm{Fe}^{3+}$ ions, they are inactivated by an electron transfer resulting in $\mathrm{Fe}^{2+}$ and molecular oxygen (Choe \& Min, 2005).

Dehydroascorbic acid contents increased markedly compared to other media tested. This increase was already found at the beginning indicating fast reaction of $\mathrm{Fe}^{3+}$ ions (Fig. 4). The accelerated oxidation to dehydroascorbic acid had however no influence on the overall vitamin $C$ content $(\mathrm{AA}+\mathrm{DHA})$ at the beginning, since no significant degradation was found. The hydrolysis of dehydroascorbic acid proceeded to a significant extent, only in the course of time and might be dependent on the production of reactive oxygen species. Acceleration of the oxidation of ascorbic acid to dehydroascorbic acid as well as of the hydrolysis of dehydroascorbic acid by $\mathrm{Fe}^{3+}$ ions was also ascertained by Serpen and Gökmen (2007).

With a view to understand the role of $\mathrm{Fe}^{3+}$ ions in a real food matrix, $100 \mu \mathrm{mol} \mathrm{kg}{ }^{-1}$ of $\mathrm{Fe}^{3+}$ ions were added to apple purée. As in apple purée without added $\mathrm{Fe}^{3+}$ ions, oxygen was depleted within 60 min (Supplementary data/Fig. 10). The equilibrium between ascorbic acid and dehydroascorbic acid was, like in water containing $\mathrm{Fe}^{3+}$ ions, already initially shifted to dehydroascorbic acid. At the end, the vitamin $C$ loss in apple purée with $\mathrm{Fe}^{3+}$ ions was not elevated compared to apple purée without additional $\mathrm{Fe}^{3+}$ ions (Fig. 4). As oxygen was depleted in apple purée, an oxygen lack might have caused this non-effect of $\mathrm{Fe}^{3+}$ ions.

\subsection{Impact of the concentration of ascorbic acid}

The impact of the concentration of ascorbic acid was studied in water with $20 \mu \mathrm{mol} \mathrm{kg}{ }^{-1} \mathrm{Fe}^{3+}$ ions in the presence of three different ascorbic acid concentrations ( 3,6 and $12 \mathrm{mmol} \mathrm{kg}^{-1}$ ). The depletion of oxygen did not increase with the concentration of ascorbic acid (Supplementary data/Fig. 11) and relative vitamin C degradation that is, the degradation expressed as percentage of the initial value, did not differ within the uncertainty of values (Fig. 5). This is in accordance to the result of Oey et al. (2006) who report that concentration of ascorbic acid does not influence the degradation pace of the aerobic pathway.

\subsection{Anaerobic vs. aerobic degradation}

To study the effect of oxygen deprivation, the experimental setup was changed to glass tubes which permitted to maintain an airtight system. The experiment was first conducted under aerobic condition, that is without oxygen substitution, in water containing $20 \mu \mathrm{mol} \mathrm{kg} \mathrm{kg}^{-1}$ of $\mathrm{Fe}^{3+}$ and $3 \mathrm{mmol} \mathrm{kg}{ }^{-1}$ of ascorbic acid. Under this condition, vitamin $\mathrm{C}$ degraded significantly after $6 \mathrm{~h}$ at $80^{\circ} \mathrm{C}$ (Fig. 6). With a view to verify if $\mathrm{Fe}^{3+}$ ions interact with ascorbic acid also in the absence of oxygen, oxygen was substituted by nitrogen. No degradation occurred (Fig. 6). $\mathrm{Fe}^{3+}$ ions did not lead directly to degradation of ascorbic acid. Neither $\mathrm{Fe}^{3+}$ ions nor oxygen alone (complete stability of ascorbic acid was observed in ultrapure water, Fig. 2) were able to trigger ascorbic acid degradation. Their combination appeared to be crucial. A marked protective effect, when oxygen is replaced by argon in a solution containing $\mathrm{Cu}^{2+}$ ions, was also observed by Boatright (2016).

Subsequently, the effect of oxygen deprivation was assessed in the supernatant of centrifuged apple purée. This medium was chosen as oxygen is difficult to eliminate from viscous apple purée and vitamin $C$ degradation proceeds at the same pace in these two media (Herbig, submitted). Like in water with $20 \mu \mathrm{mol} \mathrm{kg}{ }^{-1} \mathrm{Fe}^{3+}$ ions, vitamin $\mathrm{C}$ degraded under aerobic but not under anaerobic conditions. Oxygen seemed, also in apple purée, to be fundamental 

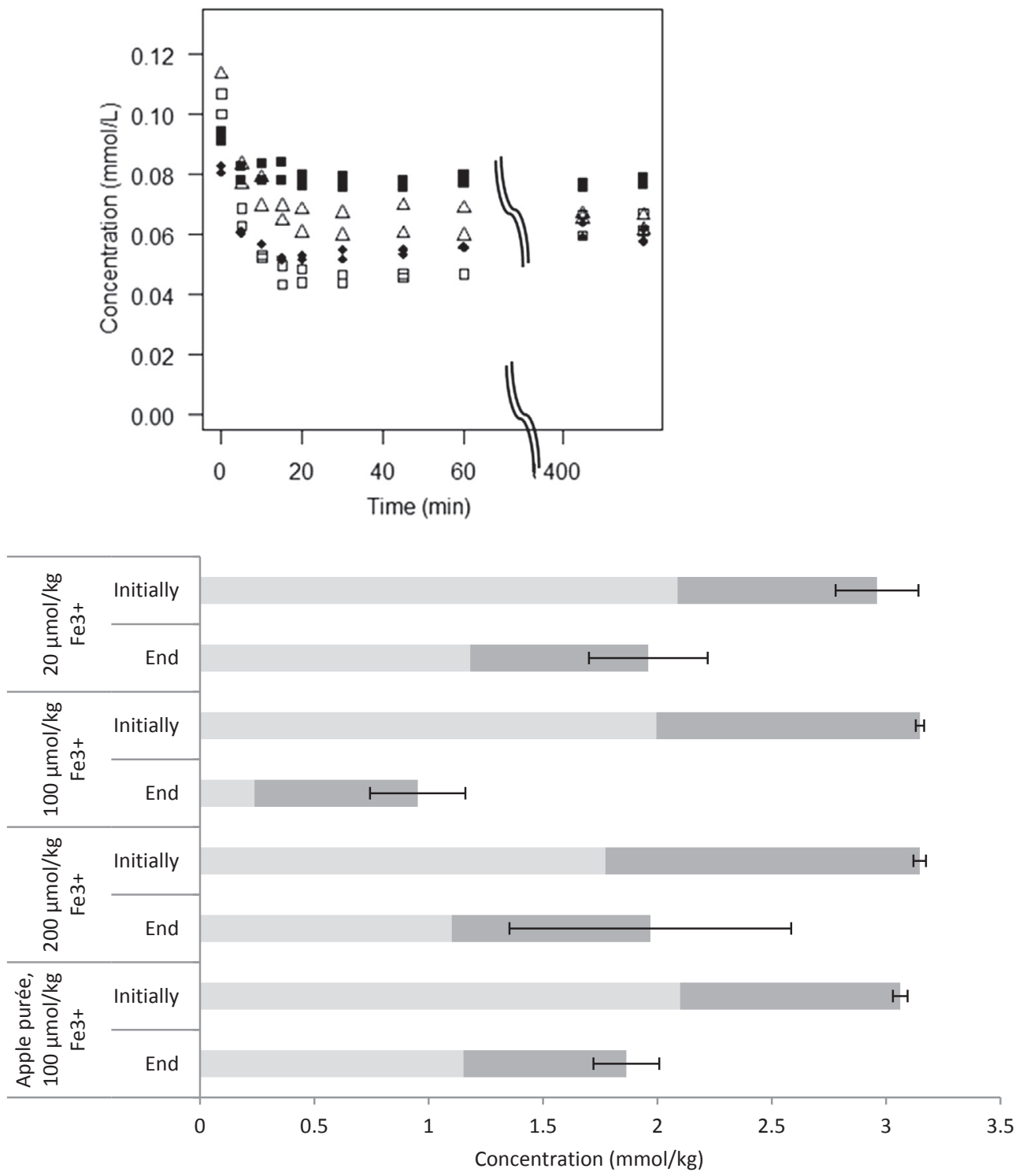

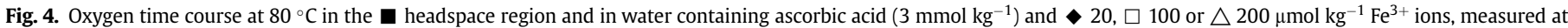
the bottom respectively. Related vitamin C loss illustrated as bar plots, light grey: ascorbic acid, dark grey: dehydroascorbic acid.

to initiate vitamin $\mathrm{C}$ degradation.

\subsection{Influence of temperature}

The impact of decreasing temperature on oxygen values and related vitamin $C$ degradation was studied in water containing

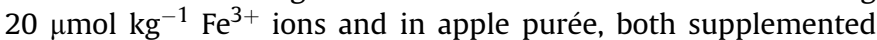
with $3 \mathrm{mmol} \mathrm{kg}^{-1}$ ascorbic acid. Decreasing temperature to 70 or $60{ }^{\circ} \mathrm{C}$ led, as expected (Penicaud et al., 2012), in the headspaces to increased oxygen contents compared to $80^{\circ} \mathrm{C}$.

In water with $20 \mu \mathrm{mol} \mathrm{kg}^{-1} \mathrm{Fe}^{3+}$ ions, similar oxygen behavior at $70{ }^{\circ} \mathrm{C}$ and $60{ }^{\circ} \mathrm{C}$ as at $80{ }^{\circ} \mathrm{C}$ was observed. Oxygen levels first dropped and then increased again without reaching the level of the headspace (Supplementary data/Fig. 12). Oxygen contents at the bottom and the surface were not significantly different. Oxygen stayed abundant over the whole period. Furthermore, vitamin $\mathrm{C}$ was degraded to the same extent at $70{ }^{\circ} \mathrm{C}$ and $60{ }^{\circ} \mathrm{C}$ compared to $80{ }^{\circ} \mathrm{C}$ with a loss of $30 \%$.

As at $80^{\circ} \mathrm{C}$, oxygen in apple purée was depleted more than in water at $70{ }^{\circ} \mathrm{C}$ and $60{ }^{\circ} \mathrm{C}$ (Fig. $7 \mathrm{~A}+\mathrm{B}$ ). The oxygen decrease proceeded however slower at $70^{\circ} \mathrm{C}$ and $60{ }^{\circ} \mathrm{C}$ compared to $80{ }^{\circ} \mathrm{C}$ in apple purée. The equilibrium was reached within $120 \mathrm{~min}$ at $70{ }^{\circ} \mathrm{C}$ and within $180 \mathrm{~min}$ at $60^{\circ} \mathrm{C}$. A difference between oxygen contents at the bottom and near the surface was observed not only for the time interval in which oxygen decreased continuously, but also after having reached the plateau. At the bottom, anaerobic conditions were found, which was not the case for at the surface. This might indicate faster oxygen renewal from the headspace in the surface region relative to oxygen consumption. Consistently, Penicaud et al. (2011) observed an oxygen content gradient at $20^{\circ} \mathrm{C}$ in agar gel containing ascorbic acid. Even though oxygen was consumed, which might be due to oxygen consumption of polyphenols, the vitamin $\mathrm{C}$ loss was not significant; neither at $70^{\circ} \mathrm{C}$ nor at $60^{\circ} \mathrm{C}$. Vitamin $\mathrm{C}$ degraded in apple purée only at $80^{\circ} \mathrm{C}$.

Since a temperature decrease led only in apple purée and not in water containing $\mathrm{Fe}^{3+}$ ions to higher stability of vitamin $\mathrm{C}$, it appeared that the heat-sensitivity was medium dependent. 


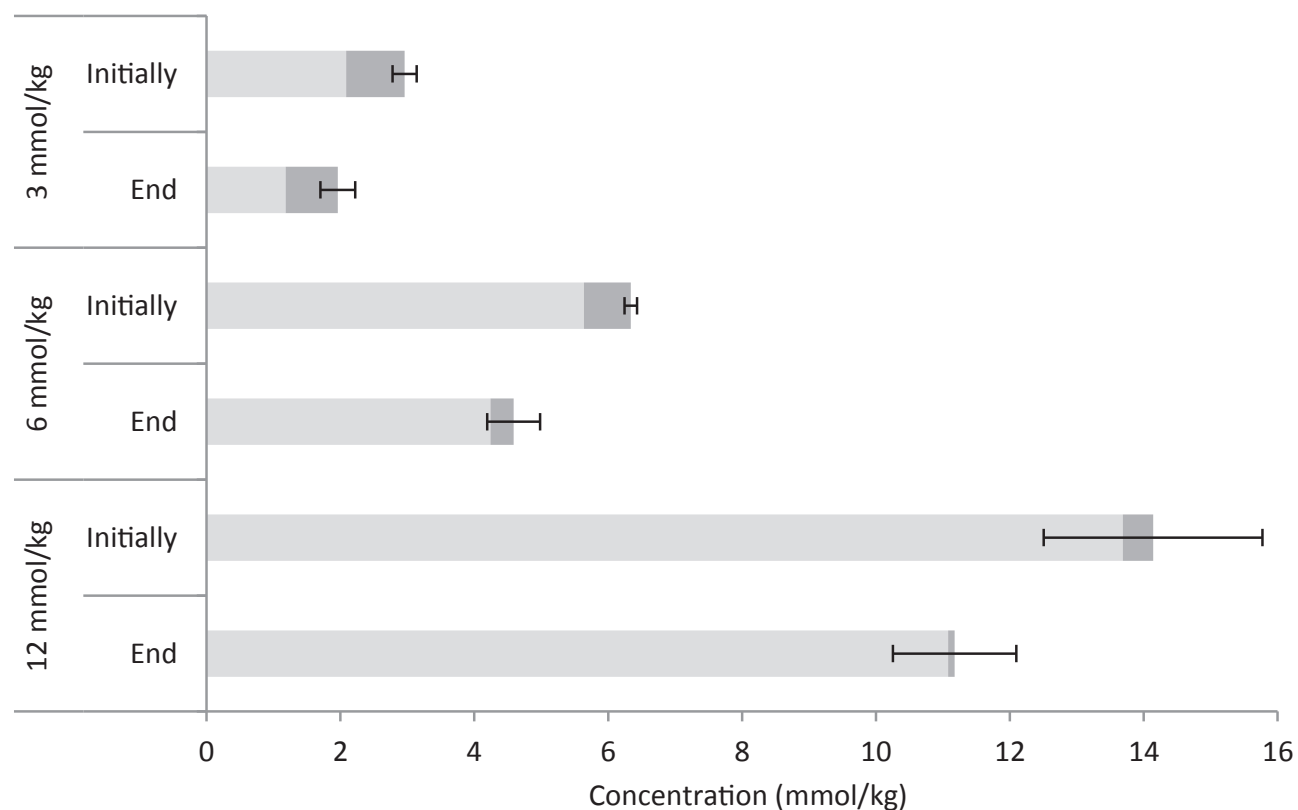

Fig. 5. Effect of the initial concentration of ascorbic acid on its degradation extent at $80^{\circ} \mathrm{C}$, light grey: ascorbic acid, dark grey: dehydroascorbic acid.

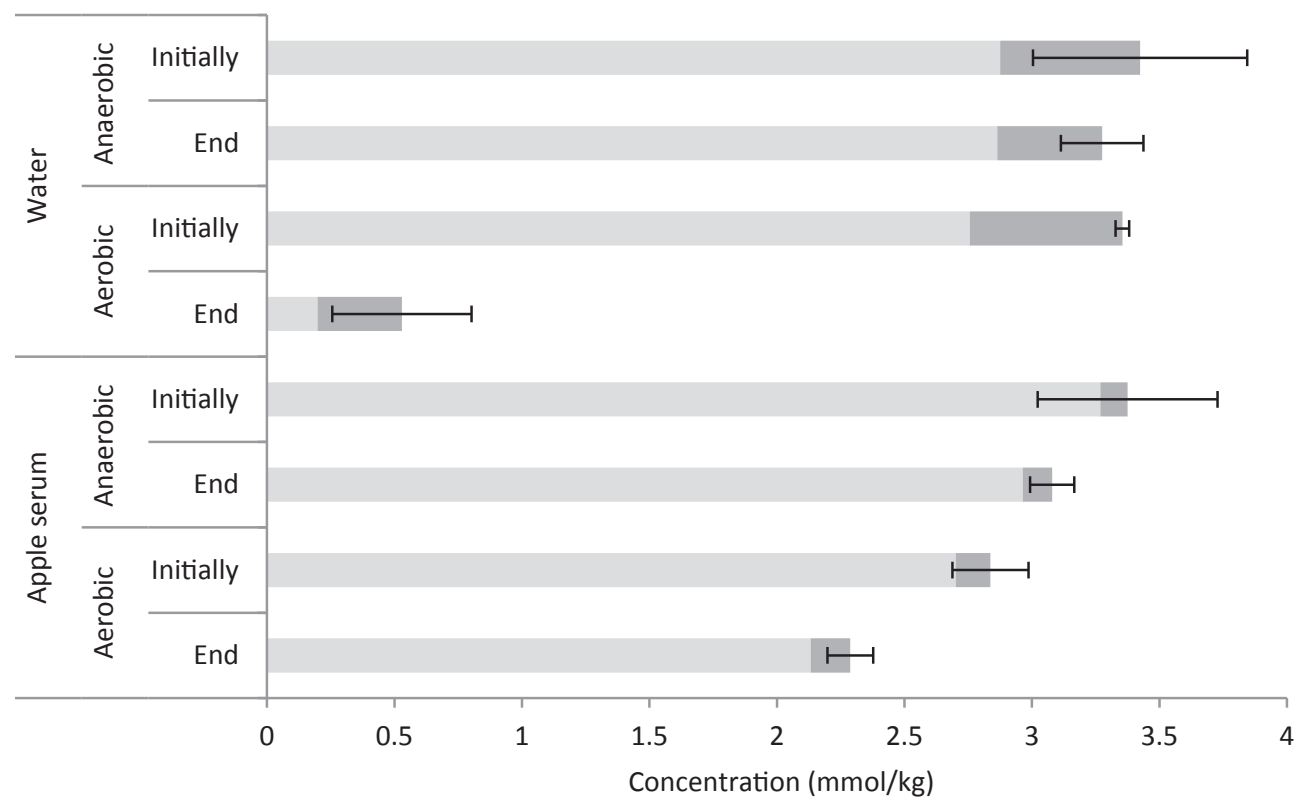

Fig. 6. Effect of oxygen deprivation on the degradation extent of vitamin $\mathrm{C}$ at $80{ }^{\circ} \mathrm{C}$ in water containing $20 \mu \mathrm{mol} \mathrm{kg}{ }^{-1} \mathrm{Fe}^{3+}$ ions and in apple serum.

\subsection{Convection and diffusion in the double walled system}

To get an idea of mixing mechanisms that occur in the double envelope system and might contribute to homogenization of oxygen or vitamin C concentration, a spatula tip of methylene blue was put on the top of water and apple purée at $80{ }^{\circ} \mathrm{C}$ respectively. Convection occurred in water which was indicated by inhomogeneous distribution of the colorant over time (Supplementary material/Fig. 13). However, spreading proceeded rapidly and thus a uniform coloration was obtained within 30 s. In the apple purée, in contrast, movement occurred only via diffusion (Supplementary material/Fig. 14). No flow marks were seen. The colorant disseminated slowly in circles around the point where it was set. Since convection was absent in viscous apple and carrot purée, limited oxygen replacement might occur in such media.

\section{Conclusion}

Vitamin C kinetics in buffer solution should be carefully interpreted, especially if the results are related to real food products. Availability of oxygen and oxidation catalysts are crucial for ascorbic acid degradation and are not the same in water, buffer solution or food products. Vitamin C was stable for $8 \mathrm{~h}$ at $80{ }^{\circ} \mathrm{C}$ in ultrapure water even though oxygen was present in excess. In citrate-phosphate buffer ( $\mathrm{pH} 3.5)$, degradation occurred, which might be linked to trace metal ions. In apple and carrot purée, in 

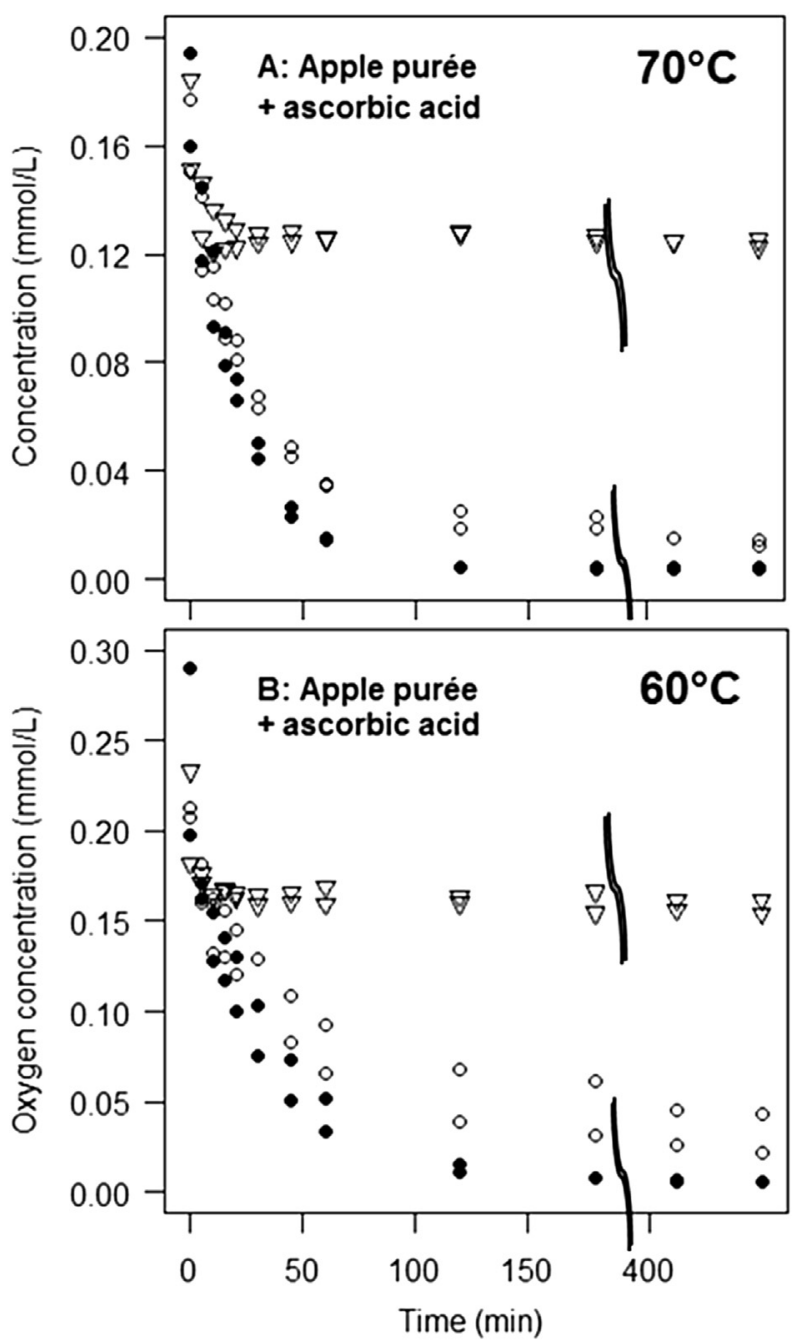

Fig. 7. Temperature effect on oxygen contents in apple purée containing ascorbic acid $\left(3 \mathrm{mmol} \mathrm{kg}{ }^{-1}\right.$ ) during heat treatment at $\mathrm{A}: 70{ }^{\circ} \mathrm{C}$ and B: $60{ }^{\circ} \mathrm{C}$ measured in the $\nabla$ headspace, and in the $\bigcirc$ surface and $\bullet$ the bottom region of the medium.

turn, oxygen was consumed entirely within 60 min. Oxygen was not replaced again, not even near the surface. As vitamin $C$ degradation was strongly linked to the availability of oxygen, the degradation mechanism in buffer and food products can be supposed to differ and explain why the heat sensitivity of vitamin $C$ depended on the medium. Vitamin $C$ was preserved completely by a temperature decrease to $60^{\circ} \mathrm{C}$ and $70^{\circ} \mathrm{C}$ in apple purée but not in water containing $20 \mu \mathrm{mol} \mathrm{kg}{ }^{-1} \mathrm{Fe}^{3+}$ ions. $\mathrm{Fe}^{3+}$ ions added to apple purée shifted the initial equilibrium of ascorbic acid to dehydroascorbic acid but did not, like in water, accelerate the total vitamin $C$ degradation what might be linked to the limited oxygen availability in apple purée. For prediction of vitamin C losses, working with real food product appears to be indispensable.

\section{Acknowledgement}

Excellent technical assistance of Claire Dargaignaratz is gratefully acknowledged.

This project has received funding from the European Union's Seventh Framework Programme for research, technological development and demonstration under grant agreement n FP7-311754.

\section{Appendix A. Supplementary data}

Supplementary data related to this article can be found at http:// dx.doi.org/10.1016/j.lwt.2016.09.033.

\section{References}

Aka, J.-P., Courtois, F., Louarme, L., Nicolas, J., \& Billaud, C. (2013). Modelling the interactions between free phenols, L-ascorbic acid, apple polyphenoloxidase and oxygen during a thermal treatment. Food Chemistry, 138(2-3), 1289-1297.

Block, G. (1991). Vitamin C and cancer prevention - The epidemiologic evidence. American Journal of Clinical Nutrition, 53(1), S270-S282.

Boatright, W. L. (2016). Oxygen dependency of one-electron reactions generating ascorbate radicals and hydrogen peroxide from ascorbic acid. Food Chemistry, 196, 1361-1367.

Bradshaw, M. P., Barril, C., Clark, A. C. Prenzler, P. D. \& Scollary, G. R. (2011). Ascorbic acid: A review of its chemistry and reactivity in relation to a wine environment. Critical Reviews in Food Science and Nutrition, 51(6), 479-498.

Buettner, G. R. (1988). In the absence of catalytic metals ascorbate does not autoxidize at pH 7-ascorbate as a test for catalytic metals. Journal of Biochemical and Biophysical Methods, 16(1), 27-40.

Choe, E., \& Min, D. B. (2005). Chemistry and reactions of reactive oxygen species in foods. Journal of Food Science, 70(9), R142-R159.

Dhuique-Mayer, C., Tbatou, M., Carail, M., Caris-Veyrat, C., Dornier, M., \& Amiot, M. J. (2007). Thermal degradation of antioxidant micronutrients in citrus juice: Kinetics and newly formed compounds. Journal of Agricultural and Food Chemistry, 55(10), 4209-4216.

Gale, C. R., Martyn, C. N., Winter, P. D., \& Cooper, C. (1995). Vitamin C and risk of death from stroke and coronary heart-disease in cohort of elderly people. British Medical Journal, 310(6994), 1563-1566.

Khan, M. M., \& Martell, A. E. (1967). Metal ion and metal chelate catalyzed oxidation of ascorbic acid by molecular oxygen. II. Cupric and ferric chelate catalyzed oxidation. Journal of the American Chemical Society, 89(26), 7104-7111.

Liebsch, G., Klimant, I., Frank, B., Holst, G., \& Wolfbeis, O. S. (2000). Luminescence lifetime imaging of oxygen, $\mathrm{pH}$, and carbon dioxide distribution using optical sensors. Applied Spectroscopy, 54(4), 548-559.

Oey, I., Verlinde, P., Hendrickx, M., \& Van Loey, A. (2006). Temperature and pressure stability of L-ascorbic acid and/or [6s] 5-methyltetrahydrofolic acid: A kinetic study. European Food Research and Technology, 223(1), 71-77.

Penicaud, C., Broyart, B., Peyron, S., Gontard, N., \& Guillard, V. (2011). Mechanistic model to couple oxygen transfer with ascorbic acid oxidation kinetics in model solid food. Journal of Food Engineering, 104(1), 96-104.

Penicaud, C., Peyron, S., Gontard, N., \& Guillard, V. (2012). Oxygen quantification methods and application to the determination of oxygen diffusion and solubility coefficients in food. Food Reviews International, 28(2), 113-145.

Serpen, A., \& Gökmen, V. (2007). Reversible degradation kinetics of ascorbic acid under reducing and oxidizing conditions. Food Chemistry, 104(2), 721-725.

Stevens, R., Buret, M., Garchery, C., Carretero, Y., \& Causse, M. (2006). Technique for rapid, small-scale analysis of vitamin $C$ levels in fruit and application to a tomato mutant collection. Journal of Agricultural and Food Chemistry, 54(17), 6159-6165.

Van Bree, I., Baetens, J. M., Samapundo, S., Devlieghere, F., Laleman, R., Vandekinderen, I.,... De Meulenaer, B. (2012). Modelling the degradation kinetics of vitamin $C$ in fruit juice in relation to the initial headspace oxygen concentration. Food Chemistry, 134(1), 207-214.

Verbeyst, L., Bogaerts, R., Van der Plancken, I., Hendrickx, M., \& Van Loey, A. (2013). Modelling of vitamin $C$ degradation during thermal and high-pressure treatments of red fruit. Food and Bioprocess Technology, 6(4), 1015-1023.

Zandi, P. P., Anthony, J. C., Khachaturian, A. S., Stone, S. V., Gustafson, D., Tschanz, J. T., ... Cache Cty Study, G. (2004). Reduced risk of alzheimer disease in users of antioxidant vitamin supplements - The cache county study. Archives of Neurology, 61(1), 82-88. 